\title{
Puerperas' knowledge regarding postpartum exercises in a tertiary hospital in the Capricorn District of Limpopo Province, South Africa
}

\author{
M O Mbombi, MCur; M K Thopola, PhD; J C Kgole, DLit et Phil \\ Department of Nursing Science, School of Healthcare Sciences, University of Limpopo, Polokwane, South Africa
}

Corresponding author: M O Mbombi (masenyani.mbombi@ul.ac.za)

\begin{abstract}
Background. Postpartum exercises (PPEs) are critical for the involution process post delivery. PPE affects the physical and psychological wellbeing of puerperas. Clinical observation shows a lack of exercise by puerperas in postnatal units.

Objectives. To determine puerperas' knowledge regarding PPE, as well as to develop a health education programme on PPE.

Methods. A quantitative, non-experimental, descriptive research design was employed. Probability random sampling was used to ensure that all puerperas had an equal opportunity to be selected. The sample comprised 50 puerperas who were admitted to a postnatal unit at a tertiary hospital in the Capricorn District, Limpopo, South Africa. The researchers distributed questionnaires that contained closedended questions to the puerperas on the days they visited the institution. Reviews of the literature and consultations with midwifery experts were conducted to ensure content validity. Data analysis was done through descriptive statistics.

Results. Our data revealed that $68 \%$ of puerperas participating in the study lacked knowledge regarding PPE, whereas $72 \%$ of puerperas were not exercising due to perineal pains, discomfort, exhaustion and a lack of educational programmes at clinics and hospitals. The study showed that there was a high rate of ignorance among puerperas regarding the importance of PPE.

Conclusion. We recommend that registered midwives initiate, develop and implement a sustainable educational programme on PPE in postnatal units.
\end{abstract}

S Afr J Obstet Gynaecol 2017;23(1):3-6. DOI:10.7196/SAJOG.2017.v23i1.1059

Exercises are an important part of daily life for many women. According to Davidson et al. ${ }^{[1]}$ postpartum exercises (PPEs) are regarded as basic therapy, which may improve the health of puerperas. Body image is a great concern for puerperas. ${ }^{[2]}$ However, most puerperas never worry about the exercises following parturition and their benefit. This suggests limited knowledge and awareness regarding PPE that might result in backache, uterine subinvolution, urinary incontinence and flabby abdominal muscles. ${ }^{[3]}$ The study findings by Gaffield et al. ${ }^{[4]}$ indicated that puerperas have limited information with regard to the importance and benefits of PPEs. Sellers ${ }^{[5]}$ asserts that physiological changes such as the weakening of the abdominal and pelvic floor muscles, stiffness, and swelling of tissues caused by trauma during delivery inhibit the performance of PPEs, which are necessary to bring the stretched abdominal and pelvic muscles back to normal. ${ }^{[6]}$ A study by Ashrafinia et al. ${ }^{[7]}$ has shown that PPEs help to strengthen pelvic and abdominal muscles, help in controlling haemorrhage and ensure a speedy uterine involution and recovery to the non-pregnant weight and physique. Davies et al. ${ }^{[6]}$ further indicated that puerperas should be engaged in PPE to reduce postpartum complications such as postpartum haemorrhage and/or puerperal sepsis. Fine et al. ${ }^{[8]}$ recommend that, in the absence of either obstetric or medical complications, puerperas should perform moderate exercises to maintain cardiopulmonary functions, muscular fitness and so that the internal structures could return to the pregravid state.

\section{Methods \\ Research design}

A quantitative, non-experimental and descriptive research design was employed in this study. ${ }^{[9]}$ This design enabled the researchers to study a selected sub-group of the population and to extrapolate the findings to the entire population in the tertiary hospital of Capricorn District. Measurements focused on specific variables, namely age, parity, knowledge and PPE, that were quantified through rating scale and frequency count. The study hypothesis was that young and educated puerperas had knowledge regarding PPE.

\section{Population and sampling}

The population was puerperas in a postnatal unit of a tertiary hospital in Capricorn District, Limpopo Province, South Africa (SA). ${ }^{[3]}$ Probability random sampling was used to ensure that all puerperas had an equal opportunity to be selected for the study. The sample study consisted of 50 puerperas who completed the questionnaire in the postnatal unit. Puerperas were assembled in one cubicle and small papers with numbers or without numbers were placed in a box where each respondent picked a paper. Those who picked papers with numbers were included in the study and those without numbers were excluded from the study. ${ }^{[1]}$

\section{Data collection}

Questionnaires with closed-ended questions were used as a method of data collection. Puerperas were assembled in the hospital cubicle and briefed about the self-administered questionnaires with fixed alternative questions. ${ }^{[1,12]}$ Fifty puerperas completed the questionnaires, which were designed to collect demographic data (section A) as well as data on the mothers' knowledge of PPE. Data collection took 5 days.

\section{Ethical considerations}

Permission to conduct the study was requested from the Medunsa Research Ethics Committee (MREC) and from the Limpopo Department of Health and Social Development. Informed consent 
was obtained from all puerperas after explaining the goals of the investigation, as well as the possible advantages and disadvantages of participating. Participation to the study was voluntary. Each respondent signed the consent forms after the researchers had explained the purpose of the study based on the research design in their own language. Puerperas were assured of confidentiality. A number was allocated to each respondent to ensure anonymity and confidentiality.

\section{Validity and reliability}

Midwifery experts and literature reviewing ensured content validity. Pretesting of the questionnaire contributed towards reliability of the data collection instrument, measured in terms of asking about things the puerperas were likely to be able to answer and clarity of the questions.

\section{Results}

Puerperas aged 17 - 19 years had the highest lack of knowledge regarding PPE. This supported the hypothesis from the researchers. Only 2 (4\%) had knowledge about PPE. There were no differences in knowledge among puerperas between 20 and 22 years old. Fifty percent of the puerperas had knowledge regarding PPE, while the other half had no knowledge regarding PPE. Nine (18\%) puerperas between 23 and 25 years old, had no knowledge, while only 7 (14\%) had knowledge with regard to PPE. Only 1 (2\%) of the puerperas, who was between 26 and 28 years old, had knowledge with regard to PPE, while 9 (18\%) puerperas had no knowledge about puerperal exercises (Fig. 1).

Nine $(18 \%)$ puerperas who were learners in grade 10 had no knowledge about PPE and only 1 (2\%) puerpera in grade 11 had no knowledge of PPE. Five (10\%) puerperas who were learners in grade 11 had knowledge of PPE. Fifteen (30\%) puerperas in grade 12 lacked knowledge about PPE and only 5 (10\%) had knowledge about PPE. Nine (18\%) post-grade 12 puerperas had no knowledge while only 6 (12\%) had knowledge about PPE (Fig. 2).

Nineteen $(38 \%)$ puerperas who were para 1 had no knowledge regarding PPE. Fifteen (30\%) puerperas who were para 2 had knowledge, while 8 (16\%) had no knowledge regarding PPE. Seven (14\%) puerperas who were para 3 had no knowledge and only 1 (1\%) had knowledge regarding PPE (Fig. 3).

Twenty-one (42\%) puerperas who had normal vaginal deliveries had no knowledge and only $4(8 \%)$ puerperas had knowledge

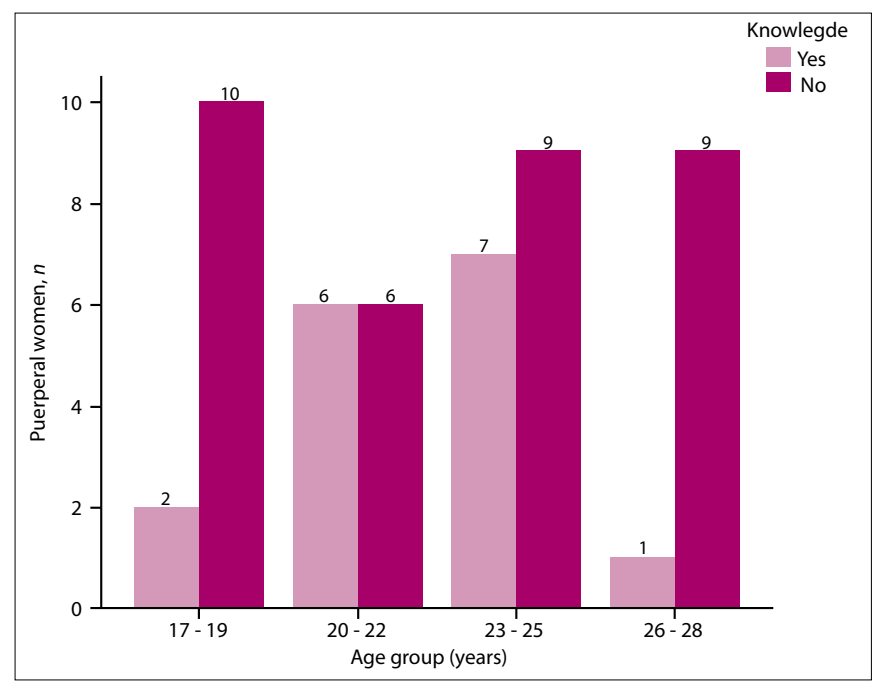

Fig. 1. Puerperas' knowledge regarding PPE in relation to their age group.

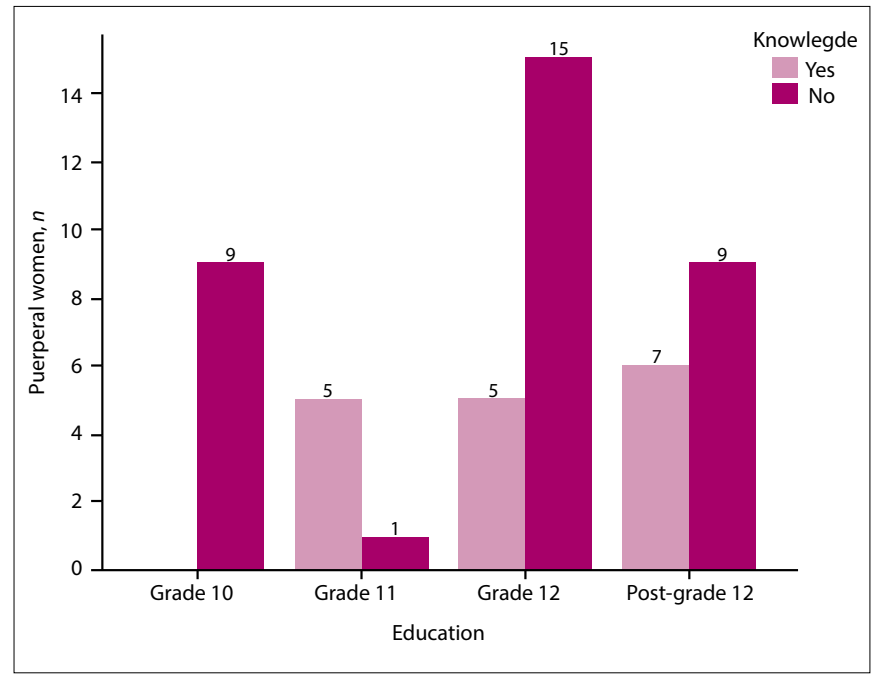

Fig. 2. Puerperas' knowledge regarding PPE in relation to their level of education.

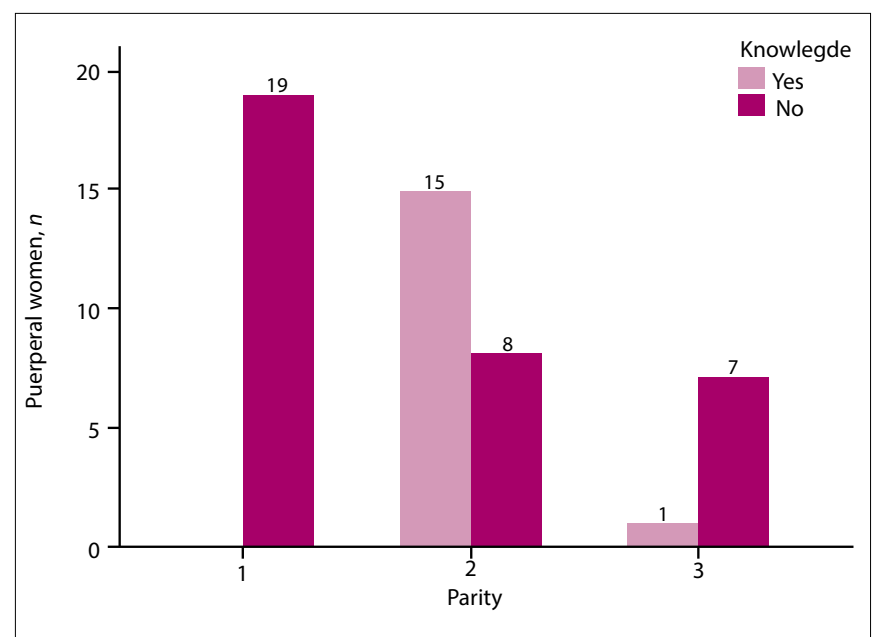

Fig. 3. Puerperas' knowledge regarding PPE in relation to their parity.

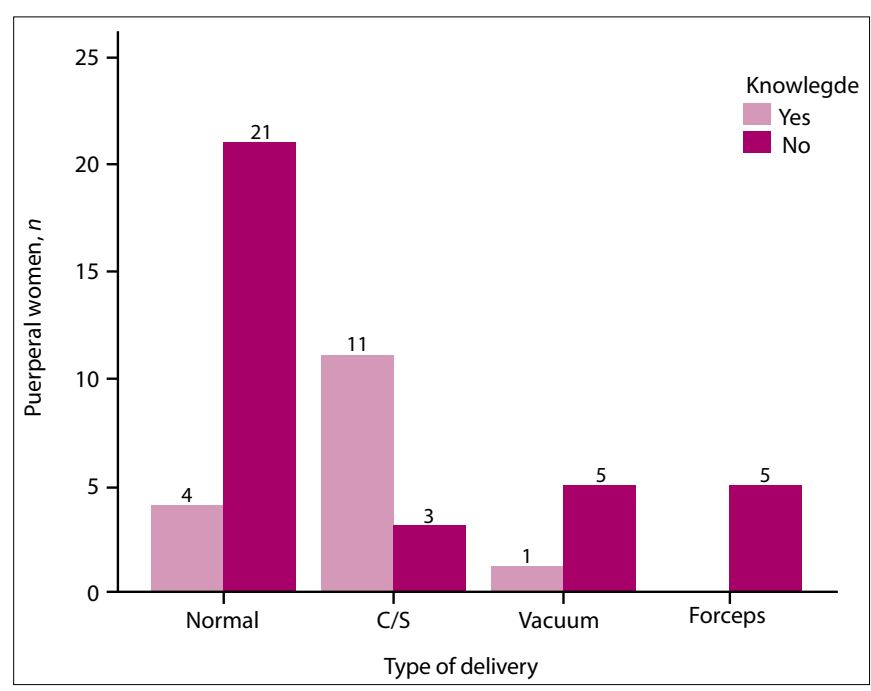

Fig. 4. Puerperas' knowledge regarding PPE in relation to the type of delivery.

regarding PPE. Eleven (22\%) puerperas who delivered by caesarean section $(\mathrm{C} / \mathrm{S})$ had knowledge, whereas three who delivered by $\mathrm{C} / \mathrm{S}$ had no knowledge regarding PPE. Five (10\%) puerperas who delivered by vacuum extraction had no knowledge, and only one 
Table 1. Educational programme for PPE

\begin{tabular}{|c|c|c|c|}
\hline Day & Type of exercise & Importance & Activities \\
\hline \multirow[t]{3}{*}{1} & Pelvic floor (Kegels) & $\begin{array}{l}\text { Strengthen the muscles of the pelvic } \\
\text { floor } \\
\text { Regain full bladder control } \\
\text { Prevent puerperal stress } \\
\text { incontinence } \\
\text { Ensure sexual satisfaction }\end{array}$ & $\begin{array}{l}\text { Squeeze/tighten the anal sphincter for } 3 \text { seconds, relax the } \\
\text { muscle for } 3 \text { seconds, and squeeze again. } \\
\text { Begin with } 103 \text {-second squeezes, thrice a day and increase } \\
\text { gradually. Work up to } 50 \text { - } 100 \text { Kegels per day. }\end{array}$ \\
\hline & Abdominal breathing & $\begin{array}{l}\text { Increase the tonicity of the deep } \\
\text { transverse muscles }\end{array}$ & $\begin{array}{l}\text { Lying supine, inhale deeply using abdominal muscles to expand } \\
\text { the abdomen. } \\
\text { Exhale slowly through pursed lips while tightening the } \\
\text { abdominal muscles. } \\
\text { Repeat } 2 \text { - } 3 \text { times. }\end{array}$ \\
\hline & Abdominal tightening & Strengthen abdominal muscles & $\begin{array}{l}\text { Lie on back with knees bent. } \\
\text { Tighten abdominal and buttock muscles and allow pelvis to tilt } \\
\text { upwards. }\end{array}$ \\
\hline \multirow[t]{3}{*}{2} & Ankle/foot circulation & $\begin{array}{l}\text { Enhance circulation, reduce oedema } \\
\text { and prevent deep-vein thrombosis }\end{array}$ & $\begin{array}{l}\text { Do ankle circles clockwise and anti-clockwise in different } \\
\text { positions, such as sitting or lying down, etc. } \\
\text { Repeat circular pattern } 3 \text { - } 5 \text { times daily. }\end{array}$ \\
\hline & Leg sliding & Increase circulation in legs & $\begin{array}{l}\text { Lie on back with knees bent. } \\
\text { Do the pelvic tilt to keep back flat while sliding one heel up and } \\
\text { down the bed. }\end{array}$ \\
\hline & Arm and upper back stretch & $\begin{array}{l}\text { Relieve backache and strengthen the } \\
\text { ligaments }\end{array}$ & $\begin{array}{l}\text { Raise arms over head with elbows straightened and palms facing } \\
\text { one another, and hold position for } 5 \text { - } 10 \text { seconds. Lower arms } \\
\text { out to the side, palms facing downward, while maintaining a } \\
\text { straight back. }\end{array}$ \\
\hline \multirow[t]{4}{*}{$3-7$} & Abdominal strengthening & Strengthen the abdominal muscles & $\begin{array}{l}\text { Lie on back with knees bent and feet flat on the floor. } \\
\text { Slowly move chin to chest and raise the head and shoulders until } \\
\text { the neck is } 15-20 \mathrm{~cm} \text { off the floor, while one arm is stretched } \\
\text { out in front of the body. }\end{array}$ \\
\hline & Straight curl-ups & Strengthen the abdominal muscles & $\begin{array}{l}\text { Lie on back with knees bent. } \\
\text { Breathe in slowly through nose. } \\
\text { Tuck chin in and raise head while hands are pointed toward the } \\
\text { knees. } \\
\text { Exhale and lift shoulders off the floor. Hold the position for } 5 \\
\text { seconds. } \\
\text { Inhale and slowly lower body to the count of five. }\end{array}$ \\
\hline & Sit-ups & Strengthen the abdominal muscles & $\begin{array}{l}\text { Elevate head with a pillow and bend knees. Tuck chin in, exhale } \\
\text { and reach towards the knees. } \\
\text { Hold the position for } 5 \text { seconds and inhale as you release. Repeat } \\
3 \text { - } 5 \text { times. }\end{array}$ \\
\hline & Aerobic activity & $\begin{array}{l}\text { Promote cardiorespiratory and } \\
\text { muscular fitness }\end{array}$ & $\begin{array}{l}\text { Repeat all the above exercises and start to initiate gentle aerobic } \\
\text { activities, such as walking, as soon as you are able to tolerate } \\
\text { them, within } \sim 1 \text { week, where possible. } \\
\text { Vigorous aerobic activity can usually be resumed after your } \\
\text { postpartum check-up. }\end{array}$ \\
\hline
\end{tabular}

(2\%) had knowledge regarding PPE. All 5 (10\%) puerperas who delivered by forceps had no knowledge regarding PPE (Fig. 4).

\section{Discussion}

The results of the study indicated that 18 (36\%) puerperas from the sample were not exercising due to perineal pains and discomfort experienced following labour and delivery. Table 1 recommends the types of exercises and also contains information on various exercises to improve puerperas knowledge regarding PPE. Downs et al. ${ }^{[2]}$ hold that puerperas fail to initiate PPE because of exhaustion, perineal pains and discomfort that result from a sutured perineum. The study revealed that $34(68 \%)$ puerperas lacked knowledge regarding PPE and there were no educational programmes offered to them either at the clinic level during puerperal care or at the hospital after delivery. However, 4 (8\%) of the puerperas engaged actively in PPE.

The findings also indicated that puerperas were unable to understand the significance of exercising after delivery. Twenty (40\%) puerperas reported that breastfeeding could return their bodies to the pregravid state. Only 11 (22\%) puerperas had knowledge that through PPE, their bodies could return to the pregravid state. Nineteen (38\%) puerperas reported that eating a normal balanced diet could return their bodies to the non-gravid state. Only $3(6 \%)$ puerperas reported that other methods such as the tying of the abdomen could return their bodies to the nongravid state. 
Table 2. Exercises following C/S

\begin{tabular}{lll}
\hline Day & Types of exercises & Importance \\
\hline 1 & Foot and leg & $\begin{array}{l}\text { To reduce oedema and prevent } \\
\text { deep-vein thrombosis }\end{array}$ \\
& Deep breathing & $\begin{array}{l}\text { To ensure full expansion of the } \\
\text { lungs }\end{array}$ \\
& Coughing & Helps to loosen secretions \\
& Pelvic floor, curl-up and hip & $\begin{array}{l}\text { To regain full bladder control and } \\
\text { ensure normal sexual satisfaction } \\
\text { hitching }\end{array}$ \\
Breathing and abdominal & $\begin{array}{l}\text { To promote abdominal muscle } \\
\text { contraction and tonicity, as well as } \\
\text { maintain cardio-respiratory and } \\
\text { muscular fitness }\end{array}$
\end{tabular}

\section{Activities}

Do ankle circles in different positions, when sitting and/ or lying down. Repeat circular pattern 3 - 5 times.

Exhale slowly against pursed lips, while tightening the abdominal muscles.

Patient should cough while seated, with sutures supported by both hands and/or a pillow.

Tilt the pelvis by flattening the hollow of the back on the floor and squeeze pillow between knees.

Lie down on a comfortable surface with knees bent. Relax and allow body weight to sink into the surface on which you are lying.

Contract the abdominal muscles during exhalation.

\section{Recommendations}

The findings of the study suggest that the initiation and implementation of health education programmes on PPE in postnatal units would improve the knowledge of puerperas regarding PPE. Wagner et al. ${ }^{[13]}$ hold that educational programmes can be initiated and implemented in postnatal units for the improvement of PPE and enriching the puerperas' knowledge. Table 1 outlines the recommended health education programme. Midwives should emphasise the importance of PPE so that puerperas can be assisted to regain their pregravid state.

\section{Study limitations}

The findings of this study could not be generalised to other hospitals in the Limpopo Province because the study was conducted in one tertiary hospital in the Capricorn District of Limpopo. However, the study could be replicated at other healthcare institutions.

\section{Conclusion}

The study revealed that $36(72 \%)$ puerperas did not exercise because of a lack of knowledge regarding PPE. The high rate of ignorance with regards to the importance of PPE indicates that there is an urgent need for registered midwives to initiate, develop and implement sustainable educational programmes on PPE in maternity units.

1. Davidson MC, London ML, Ladewig PW. Contemporary Maternal-Newborn Nursing Care: Nurse, Family, Community. 8th ed. USA: Pearson, 2014.

2. Downs DS, Hansenblas HA. Women's exercise beliefs and behaviours during their pregnancy and postpartum. J Midwifery Women's Health 2004;49(2):138-144. https://doi.org/10.1016/j. jmwh.2003.11.009

3. Olds S, London M. Maternal Newborn Nursing and Woman's Health Care. 7th ed. New Jersey: Upper Saddle River, 2004.

4. Gaffield ME, Egan S, Temmerman M. It's about time: WHO and partners release programming strategies for postpartum programs. Global Health Sci Pract 2014;2(1):4-9. https://doi.org/10.9745/ ghsp-d-13-00156

5. Sellers PM. Midwifery. South Africa: Juta and Company, 2004

6. Davies GA, Wolfies LA, Mottola ME, Mackinnson C. Exercise in pregnancy and the postpartum period. J Obstet Gynaecol Canada 2013;25(6):516-529.

7. Ashrafinia F, Mirmohammadali M, Rajabi H, Kazemnejad A, Sadeghniiat HK. Effect of Pilates exercises on postpartum maternal fatigue. Singapore Med J 2015;56(3):169-173. https://doi. org/10.11622/smedj.2015042

8. Fine P, Burgio K, Borello-France D, et al. Teaching and practicing of pelvic floor muscle exercises in primiparous women during pregnancy and the postpartum period. Am J Obstet Gynecol 2007;197(1):107.e1-107.e5. https://doi.org/10.1016/j.ajog.2007.02.052

9. Burns N, Grove SK. The Practice of Nursing Research: Appraisal, Synthesis and Generation of Evidence. 6th ed. Saint Louis: Saunders, 2009.

10. Brink HI. Fundamentals of Research Methodology for Health Professionals. Cape Town: Juta and Company, 2006

11. Babbie E, Mouton J. The Practice of Social Research. Cape Town: Oxford University Press, 2009.

12. LoBiondo-Wood G, Harber J. Nursing Research Methods and Critical Appraisal for Evidencebased Practice. 7th ed. New York: Mosby Elsevier Inc., 2010.

13. Wagner DL, Bear M, Davidson NS. Measuring patient satisfaction with postpartum teaching methods used by nurses within the interaction model of client health behavior. Res Theory Nurs Prac 2011;25(3):1-7. https://doi.org/10.1891/1541-6577.25.3.176 